\title{
Ecology of Micro-Organisms on Chitin Buried in Soil
}

\author{
BY N. OKAFOR* \\ School of Agriculture, University of Cambridge
}

(Received 20 July 1965)

SUMMARY

The quantitative ecology of micro-organisms developing on pieces of chitin buried in soil was studied by systematically recording morphological groups and subgroups of micro-organisms developing on them. A temperate and a tropical soil were used. Both soils were incubated at $10^{\circ}$ and $29^{\circ}$, temperatures which might be expected in the respective climatic regions from which the soils were collected. In both soils the organisms most frequently observed at $10^{\circ}$ were fungi and bacteria; at $29^{\circ}$ actinomycetes, nematodes and protozoa were also observed, besides fungi and bacteria. The main differences in the nature of organisms from both soils observed on chitin was in the subgroups rather than in the major groups.

\section{INTRODUCTION}

Chitin is a polymer of $\mathbf{N}$-acetyl-D-glucosamine. Structurally, it is very similar to cellulose, from which it differs only in the possession of nitrogen within its structure (see Whistler \& Smart, 1953). Among plants chitin is found in the cell walls of most fungi and green algae; in animals it is present in annelids, arthropods, molluses and, to a lesser extent, in coelenterates and nematodes (Richards, 1951; Rudall, 1955; Tracey, 1955). The cysts and testae of certain protozoa are also known to contain chitin (Sacchs, 1956).

Many members of these groups of organisms are present in soil (Gilman, 1957; Kevan, 1955; Kuhnelt, 1961; Salt, 1953; Sandon, 1927) and therefore the soil must contain large quantities of chitin.

The ecology of soil micro-organisms on chitin has been studied by Jensen (1932), Skinner \& Dravis (1937) and by Veldkamp (1955). All three studies were carried out with the dilution plate technique in which samples of soil collected from different areas of a field are bulked and a suspension in a liquid medium plated out on a suitable agar medium. The criticisms of this method are briefly that the technique selects the lighter microbial propagules and even among these, only those which will grow on the medium employed; finally the micro-habitats in which microorganisms exist in the soil are destroyed in the bulking process.

This paper describes a study of the ecology of soil micro-organisms on chitin using the direct microscopic method (Tribe, 1957). Tribe's original method was modified to place the observations on a quantitative basis by using the latest ideas from the ecology of higher organisms or by modifying these to suit the circumstances of soil microbiology. A temperate soil and a tropical soil were used (Fig. 1), both incubated at $10^{\circ}$ and at $29^{\circ}$, temperatures likely to occur in the two regions. While

* Present address : Department of Microbiology, University of Nigeria, Nsukka, Eastern Nigeria.

Vol. 44, No. 2 was issued 14 September 1966 
the study under description was in progress Gray \& Bell (1963) published their study on the ecology of micro-organisms on 'chitin' using a modification of the direct microscopic method. However, their substrate was only partially purified; furthermore, their experiment lasted for only 11 days, whereas the present experiment was carried on for 100 days.

Although the present study was primarily ecological the opportunity was taken to observe the rates of decomposition of chitin in the two soils.

\section{METHODS}

Chitin. Chitin was prepared from the dorsal cover of the shell of the cuttlefish (Sepia officinalis L). Briefly, this consisted of decalcifying the shell in $10 \% \mathrm{HCl}$, Okafor (1965). The resulting chitin-protein complex was deproteinized for $6 \mathrm{~h}$ in excess $10 \% \mathrm{NaOH}$ at $103^{\circ}-105^{\circ}$ in an autoclave. Chitosan (Foster \& Webber, 1960) was removed in $5 \% \mathrm{HCl}$.

Table 1. Properties of soils used in the experiment

\begin{tabular}{lcc}
\multicolumn{1}{c}{ Property } & Temperate soil & Tropical soil \\
PH & $\mathbf{6 \cdot 2}$ & $\mathbf{5 \cdot 3}$ \\
Lime requirements & 15 & 30 \\
Mg (p.p.m.) & 14 & 11 \\
Na (p.p.m.) & $\mathbf{3 5}$ & 20 \\
Ca (\%) & $0 \cdot 19$ & $0 \cdot 015$ \\
N (\%) & $0 \cdot 16$ & $0 \cdot 06$ \\
Organic matter (\%) & $2 \cdot 4$ & $1 \cdot 0$ \\
C.f. & $4 \cdot 0$ & $2 \cdot 0$ \\
Soil type & Organic sandy & Loamy coarse \\
& loam & sand
\end{tabular}

Soils. The soils were collected from the University Farm, Cambridge, England, and from Moor Plantation, Ibadan, Nigeria. For convenience the soil collected from the University Farm, Cambridge, will hereinafter be referred to as Temperate Soil and that collected from Moor Plantation, Ibadan, Nigeria, as Tropical Soil. The properties of both soils are given in Table 1.

Burial of chitin in soil. Chitin, about $\mathbf{0 . 2 5} \mathbf{~ m m}$. thick, was cut into square pieces approximately $0.5 \times 0.5 \mathrm{~cm}$. and held on $\frac{5 "}{8}$ No. 2 coverslips with a drop of water. The chitin-bearing coverslips were themselves held back to back with a drop of water and arranged vertically in two tiers in a $5.0 \times 2.5 \mathrm{~cm}$. cylindrical glass bottle. Three pairs were arranged in the lower tier and two in the upper, at right angles to the lower (Fig. 2). Arranged in this way $15 \mathrm{~g}$. of soil were found sufficient to completely bury all the coverslips. Ten chitin films were thus present in each tube. The soil in each tube was moistened to $60 \%$ of its moisture holding capacity, the level regarded as optimum for most soil organisms (Chase \& Gray, 1957). To provide aeration, two holes $(1 \cdot 0-1 \cdot 5 \mathrm{~mm}$. diameter) were made opposite each other on the plastic lids of the bottles. Both soils were incubated at $29^{\circ}$ and $10^{\circ}$. Moisture losses were made good during the course of the experiment by adding known weights of distilled water to the bottles. The weight of water added at each given time was the average of the weight losses up to that time from three bottles selected at the beginning of the experiment. 
Recovery of chitin films. At given intervals the contents of the tubes were gently eased out by tapping the side of the tubes with a finger. Done this way, the contents emerged as a cylindrical body. The coverslips with their adhering chitin pieces were then gently dissected out from the soil in a sterile Petri dish with sterile needles and forceps. Where possible two pieces approximately $0.1 \times 5 \mathrm{~cm}$. and $0 \cdot 1 \times$ $4 \mathrm{~cm}$. were cut from two adjacent sides of each chitin film for the isolation of microorganisms. The rest of the recovered chitin pieces, approximately $0.4 \times 0.4 \mathrm{~cm}$. in dimension, were allowed to air-dry at room temperature.

Sometimes a piece of chitin which had been incubated in soil adhered more closely, on recovery, to the surrounding soil than to the coverslip on which it was

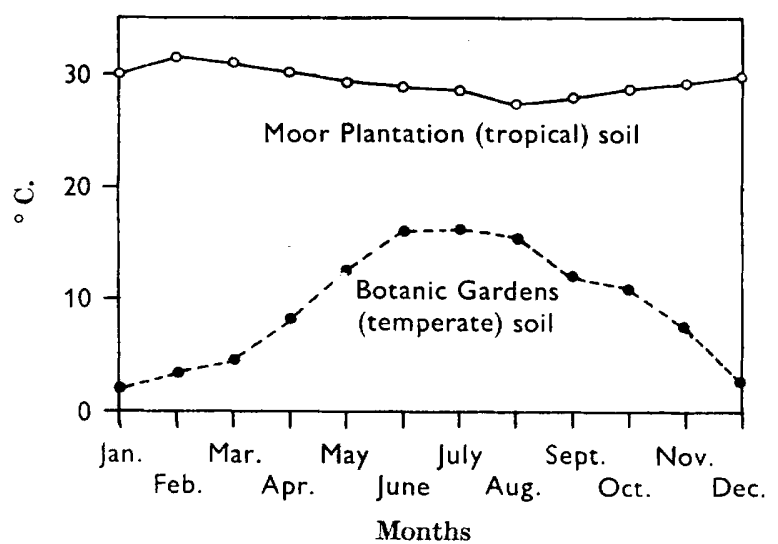

Fig. 1

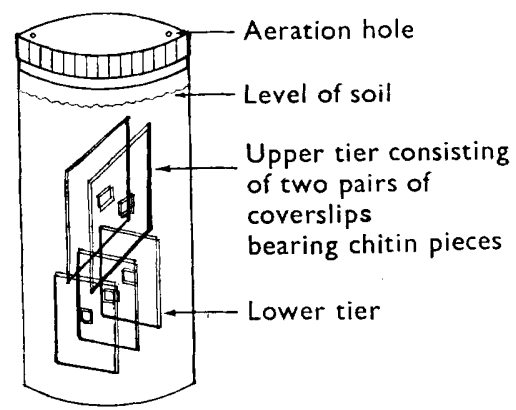

Fig. 2

Fig. 1. Average monthly temperature of soil at $1 \mathrm{ft}$. depth at the Botanic Gardens, Cambridge (1960-62) and Moor Plantation, Ibadan, Nigeria (1961-62). Soils used in the experiment were collected at 6 in. depth, but temperatures at this depth were not available.

Fig. 2. Arrangement of chitin-bearing coverslips in soil in a small $(5 \cdot 0 \times \mathbf{2} \cdot \mathbf{4} \mathrm{cm}$.) cylindrical bottle.

originally supported. As attempts to recover such a chitin piece (e.g. by teasing with a needle) led to a complete destruction of the chitin piece it was usual in such cases to place the chitin piece and its adhering soil clod, chitin first, on a fresh coverslip. The soil clod was then allowed to dry in air. In many cases the chitin pieces were caused to adhere to the coverslips in this way. Three hours was found sufficient time for all chitin films and their soil clods (where present) to dry out. After drying soil particles were picked away very carefully with a pair of fine forceps.

Staining of organisms developing on chitin: The 1/1 mixture of $2 \%$ aqueous nigrosin and picro-lactophenol described by Smith (1960) tended to be absorbed by the chitin. After various trials it was found that a more dilute mixture, $1 / 10$, of $\mathbf{2} \%$ aqueous nigrosin and picro-lactophenol was more suitable, The dried chitin pieces were flooded with freshly made stain for 90-120 min. Excess stain was drained off with extreme care in order not to dislodge the organisms from their original positions on the chitin. The film was then carefully washed with lactophenol from a Pasteur pipette. 
Where over-staining occurred it was sometimes possible to remove some stain by warming the film gently in lactophenol containing $5 \%$ conc. $\mathrm{NH}_{4} \mathrm{OH}$ over a low flame. Draining and washing were then carried out as previously described. The procedure described above for dealing with over-staining was not very effective if the stain was introduced on wet chitin material, especially if the chitin material was thick.

Preparation of permanent slides. Permanent slides were prepared slides in lactophenol with coverslips sealed with 'Glyceel' (Gurr Ltd., London).

Identification of organisms. Morphological characteristics alone were used in the identification of the organisms observed on the slides. Five major groups of organisms were observed, fungi, bacteria, actinomycetes, nematodes, and protozoa. Since different members of the major groups are likely to carry out different physiological functions in soil, the major groups excepting nematodes, were further divided into subgroups, again using morphological characteristics (see Table 2).

Sampling technique. Two quadrat sizes were used in this experiment: the oilimmersion quadrat ( $\times 8$ eyepiece; $\times 100$ objective, N.A. $1 \cdot 3$ ) was used in enumerating organisms about $1.5 \mu$ in diam. or less (i.e. bacteria and actinomycetes) and the low-power quadrat $(\times 8$ eyepiece; $\times 10$ objective, N.A. $\mathbf{0} \cdot 25)$ for those with diameters larger than $1.5 \mu$ (i.e. fungi, protozoa and nematodes). Sampling was carried out in a systematic manner, the low-power quadrats (diam. $1.2 \mathrm{~mm}$. or $1200 \mu$ ) were moved $1 \mathrm{~mm}$., and the high power (diam., $0.12 \mathrm{~mm}$. or $120 \mu) 0.5 \mathrm{~mm}$. at a time, using the calibration on the mechanical stage of the microscope as a guide. Two oil-immersion quadrats were taken for every low-power one. Thus on a $0 \cdot 4 \times 0 \cdot 4 \mathrm{~cm}$. piece of chitin there were sixteen low-power and thirty-two high-power quadrats taken in a systematic manner in four parallel rows.

Quantitative expression of observations: Two methods were used to quantify the ecological observations :-

(a) Percentage frequency of occurrence: This was determined for a given time by finding as a percentage of the total number of quadrats examined on all slides the number of quadrats in which an organism occurred. This method has been used by Jensen (1934) and Gray \& Bell (1963). The percentage frequency of occurrence was determined for the major and subgroups of organisms observed on the chitin pieces.

(b) Percentage constancy of dominance: A circular graticule divided into twenty equal sectors was introduced into an eyepiece of the microscope. Organisms were regarded as 'dominant' where they occurred in ten or more random sectors in a quadrat under examination.

Percentage frequency of dominance was calculated, for a given time, by finding as a percentage of all fields examined the number of fields in which an organism was dominant. This expression was not itself used to express quantitatively the ecological observation made in this experiment, but was determined only as part of the further calculations shown below.

Frequency determinations do not take into account the evenness or lack of evenness of distribution of the organisms from one chitin piece to another. This will be illustrated by an example. Suppose a batch of ten chitin pieces was recovered from soil at a given time and that twenty quadrats were present per piece (for simplicity let all the quadrats belong to low-power size). Suppose also that the organism under consideration were present on only two pieces and completely absent on the 
Table 2. Symbols designating, and identity of, organisms observed on chitin pieces recovered from soil

\begin{tabular}{|c|c|}
\hline Symbc & Description of organism \\
\hline F & Fungal hyphae \\
\hline $\mathbf{F}$ & Septate hyphae, usually thin: $3-6 \mu$ \\
\hline $\mathbf{F}$ & Aseptate hyphae (Pl. 1, fig. 5) \\
\hline B & Bacteria \\
\hline B & Coccoid bacteria up to $1 \cdot 3 \mu$ in diameter \\
\hline B & Rod and coccoid-rod shaped, $0 \cdot 7-1 \cdot 0 \times 1-2 \mu$ \\
\hline $\mathbf{B}$ & $\begin{array}{l}\text { Large elliptical bacteria } 1 \cdot 0-1 \cdot 5 \times 2-4 \mu \\
\text { (Pl. 2, fig. 4) }\end{array}$ \\
\hline B & $\begin{array}{l}\text { Long rod-like bacteria, } 0 \cdot 8-1 \cdot 3 \times 10 \mu \text { length; } \\
\text { often bearing a spore-like structure at one end } \\
\text { and usually occurring along with B } 3 \text { (Pl. } 2 \text {, } \\
\text { fig. 5) }\end{array}$ \\
\hline B & $\begin{array}{l}\text { Small rods, which presented a characteristic } \\
\text { uniformly closely packed background; individua } \\
\text { cells, } 0 \cdot 3-0.5 \times 0 \cdot 6-0.8 \mu\end{array}$ \\
\hline B & $\begin{array}{l}\text { Large spherical bacteria (2-4 } \mu \text { in diameter) } \\
\text { enclosed in angular sac-like structures with } \\
\text { distinct walls; sacs, } 25-40 \mu \text { across (Pl. } 2 \text {, } \\
\text { fig. 1) }\end{array}$ \\
\hline B & $\begin{array}{l}\text { Ovoid to rod-like bacteria enclosed in saes, } \\
10-40 \mu \text { across; walls of sacs indistinct }\end{array}$ \\
\hline B & $\begin{array}{l}\text { Coccoid bacteria arranged in groups of } 4,6 \text { or } 8 \\
\text { and rarely of two, enclosed in a non-staining } \\
\text { capsule. Groups were spherical to ovoid and } \\
\text { measured } 3-4 \times 5-8 \mu(P 1.1 \text {, fig. 3) }\end{array}$ \\
\hline B & Long thin bacteria, $0 \cdot 6 \times 6-16 \mu$ \\
\hline A & Actinomycetes \\
\hline A & $\begin{array}{l}\text { Actinomycete hyphae usually } 1 \cdot 0-1 \cdot 6 \mu \text { or } \\
\text { slightly larger, with no attached sporing } \\
\text { structures in the quadrat examined (PI. 1, fig. } 4\end{array}$ \\
\hline & $\begin{array}{l}\text { Actinomycetes with aerial sporing structures } \\
\text { consisting of spores arranged in spirals }\end{array}$ \\
\hline
\end{tabular}

A 3 Actinomycete with spherical sporangia attached; sporangia usually 10-12 $\mu$ (P1. 1, fig. 8)

A4 Actinomycetes with single spherical spores attached to the hyphae
$\mathbf{P}$

P 1 Deeply staining ovoid to spherical bodies $3 \cdot 9 \mu$ wide: usually with a thin non-staining zone on the outside

P2 Spherical bodies, 9-10 $\mu$ diameter, with a deeply staining inner zone surrounded by a thick non-staining zone about 1.0 $\mu$ thick (Pl. 2, fig. 3)

P3 Lightly-staining bodies with wrinkled angular appearance, $10-12 \mu$ wide

P4 Cup-shaped bodies with a thin outer wall and darkly staining central portion (Pl. 1, fig. 2)

P5 Spherical bodies with an opening displaced to one side; diameter 65-75 $\mu$ (Pl. 1, fig. 7)

P6 Hemispherical bodies staining black
Identity and authority for claim

Probably cysts of bacteria of the order Myxobacteriales family Archangiaceae (Bergey's Manual, 1957)

Probably bacteria of the order Myxobacteriales (Bergey's Manual, 1957) Probably bacteria of the genus Sarcina

Actinomycetes of the genus Streptomyces (Bergey's Manual, 1957)

Actinomycete of the family Actinoplanaleae probably genus Actinoplanales (Bergey's Manual, 1957)

Probably belonging to the genus Micromonospora

A sample of nematodes developing on chitin incubated in the temperate soil at $29^{\circ}$ for 10 days was identified as Acroboloides sp. (Dr J. B. Goodey)

Cysts of protozoa

(Dr O. W. Heal)

Probably cysts of protozoa, probably a Colopoda species (Sandon, 1927)

Probably protozoa belonging to the genus

Hartmanella (Singh, 1952)

Testate amoebae

Centropyxis minuta

(Dr O. W. Heal)

Phryganella hemispherica

(Dr O. W. Heal) 
remaining eight. Finally, suppose that on these two slides the organism was present on all twenty quadrats, then the percentage frequency of occurrence as determined above would be

$$
\frac{20 \times 2 \times 100}{10 \times 20 \times 1}=20 \%
$$

Suppose a second batch of slides was similar in all respects to the above except that although the organism was present on all slides, it occurred on only four quadrats of a possible twenty, The percentage frequency of occurrence would be:

$$
\frac{4 \times 10 \times 100}{10 \times 20 \times 1}=20 \%
$$

Thus although the evenness of distribution of organisms under consideration was different in the two batches of slides, the same percentage frequency of occurrence was given to both. To take account therefore of the evenness of distribution the following fraction was used:

$$
\frac{\begin{array}{c}
\text { No. of slides on which organism occurred (without } \\
\text { necessarily being dominant) }
\end{array}}{\text { No. of slides examined }}
$$

The term 'percentage constancy of dominance' embraced both percentage frequency of dominance and evenness of distribution and was calculated thus:

$$
\text { Percentage frequency of dominance } \times-\begin{gathered}
\text { No. of slides on which organism } \\
\text { occurred (without necessarily being } \\
\text { dominant) }
\end{gathered}
$$

The percentage constancy of dominance was determined for only the subgroups of fungi, bacteria and actinomycetes; it was not determined for protozoa and nematodes. These latter organisms have been described as secondary decomposers (Tribe, 1957).

The usage of 'frequency', 'dominance', 'constancy' as applicable to higher plant ecology will be found in Brown (1954), Greig-Smith (1964), Hanson \& Churchill (1961), Odum (1960).

Ecology of micro-organisms on glass coverslips. Control coverslips without chitin were buried in the two soils, incubated at the two temperatures, recovered from time to time, stained and examined microscopically as already described. Glass coverslips have the disadvantage that a surface smoother than that present on chitin pieces is offered to the soil micro-organisms. Coverslips roughened by grinding, however, became completely opaque and could not therefore be used in that form; coverslips used in this experiment were untreated in any way.

Estimation of decomposition of chitin under different soil and temperature conditions. Although the work was primarlly ecological the method used lent itself admirably to assessing decomposition. A subjective estimate of decomposition of chitin pieces was obtained by noting the loss of material at the uncut edges and central portions of the chitin films. 


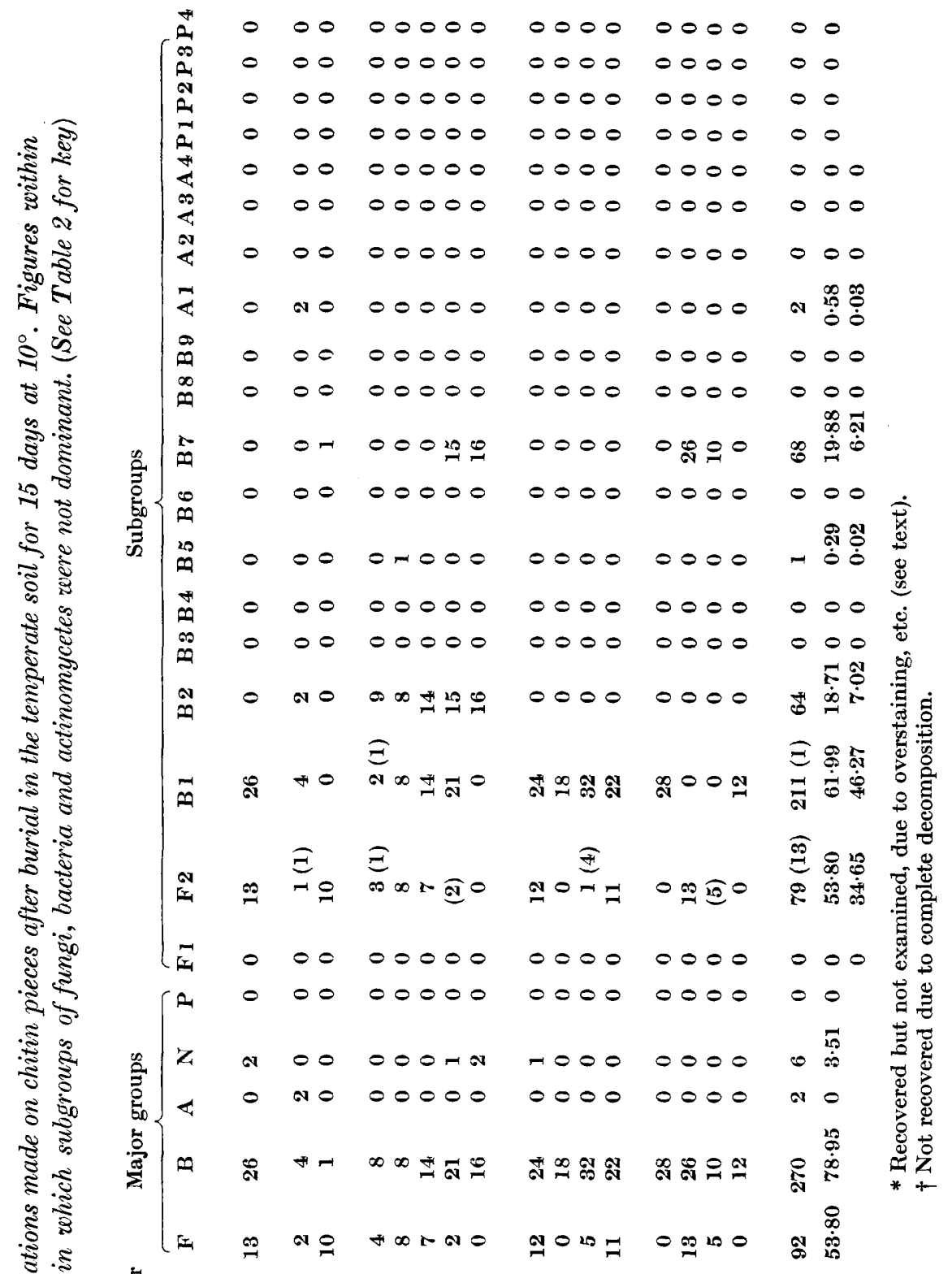

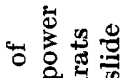

之运客

只 오

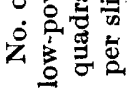

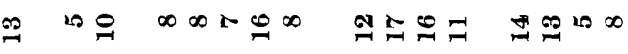

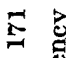

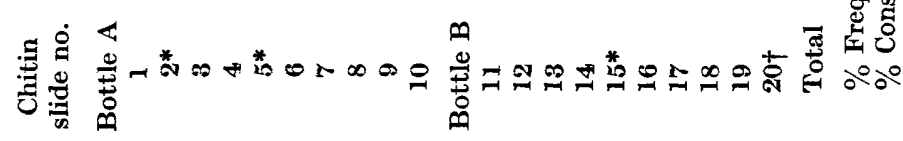




\section{RESULTS}

\section{Recovery of chitin films}

Chitin films were recovered from soil and made into slides at $5,10,15,20,25$, $30,40,50,75$ and 100 days after burial; the results of the examination of these pieces are incorporated in Figs. 3-7. Details of observations made at the 15th day on individual chitin pieces buried in the temperate soil at $10^{\circ}$ are recorded in Table 3 for illustration. Observations for other days are present elsewhere (Okafor, 1964). Slide no. 1 -slide no. 10 (see Table 3 ) were made from chitin pieces recovered from one glass bottle and the next ten from the second glass bottle.

Table 4 summarizes data on chitin pieces recovered from soil. As might be expected

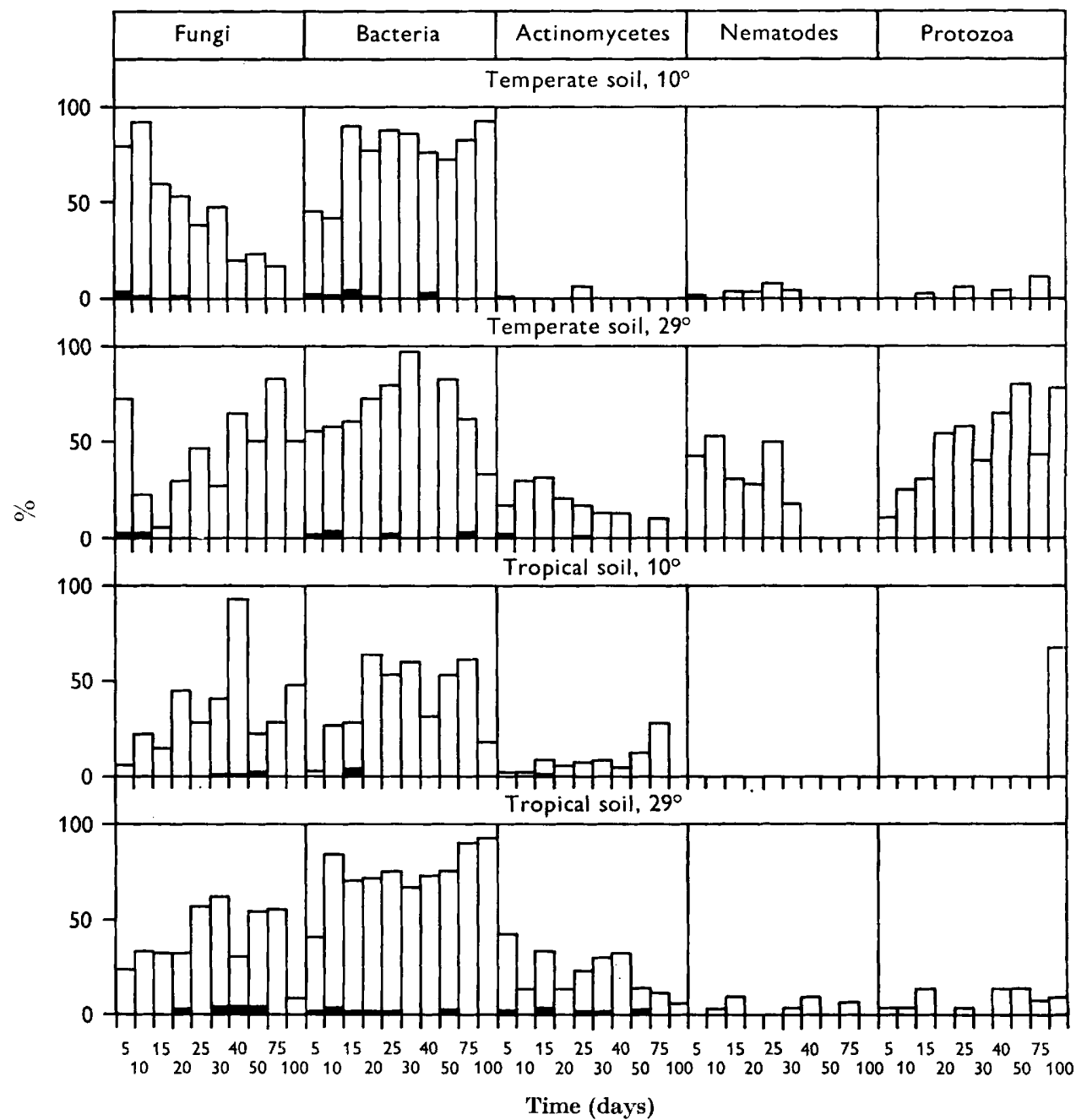

Fig. 3. Change with time of the percentage frequency of occurrence of the major groups of micro-organisms developing on chitin (empty boxes) and glass coverslip controls (black) recovered from the temperate and tropical soils. 


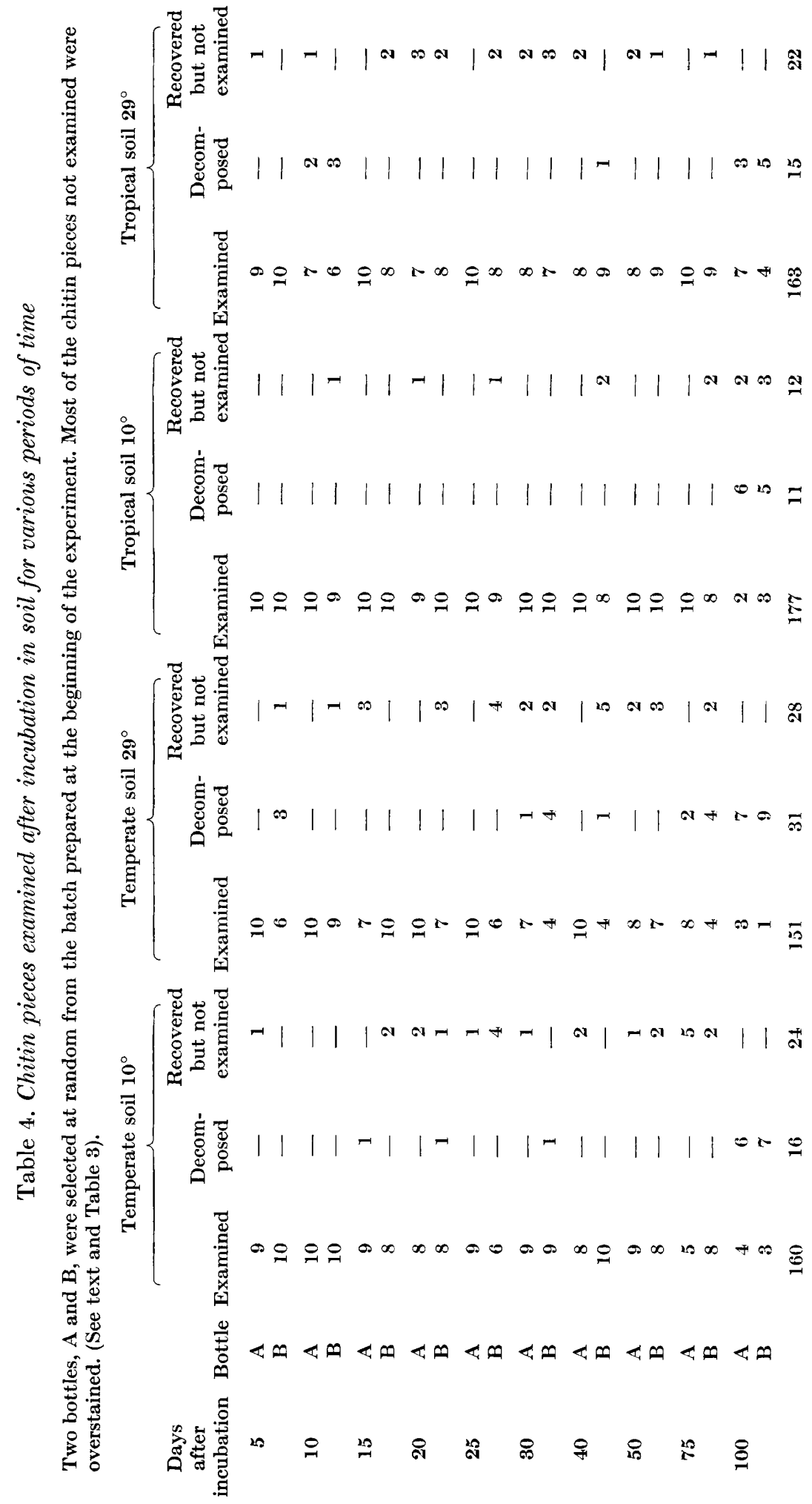


the chitin pieces that had completely decomposed increased in general with increasing length of the incubation period. The chitin pieces which could not be examined due to overstaining, etc. and the number of chitin pieces on which the data on Figs. 3-7 are based are also recorded in Table 4.

Colonization of chitin pieces buried in soil by micro-organisms

(a) Percentage frequency of occurrence of the major groups

Figure 3 summarizes observations made on the percentage frequency of occurrence of major groups of micro-organisms.

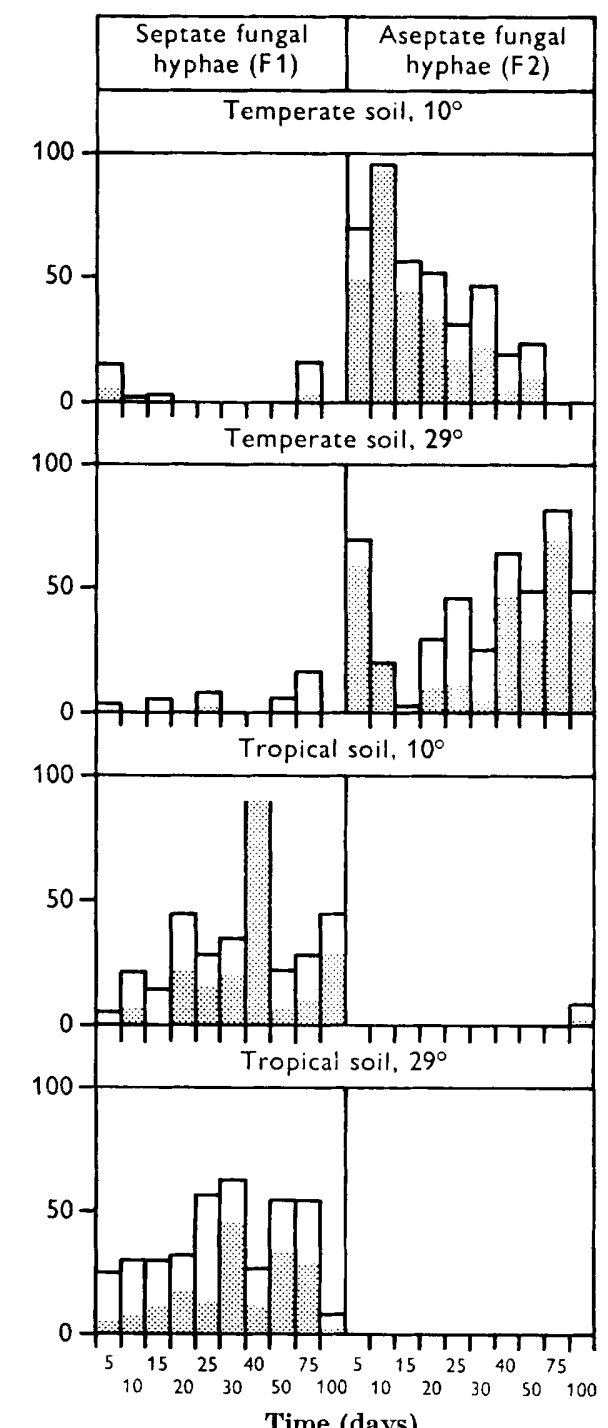

Fig. 4. Change with time in the percentage frequency of occurrence (empty boxes) and percentage constancy of dominance (dots within boxes) of the morphological sub-groups of fungi observed on chitin pieces recovered from soil. 


\section{Temperate soil}

The overall picture of the colonization by the major organisms of chitin pieces buried in the temperate soil is that fungi and bacteria are the most important organisms at $10^{\circ}$; at $29^{\circ}$ all major groups of organisms colonized chitin pieces, actinomycetes, nematodes and protozoa exhibiting a markedly higher occurrence than at $10^{\circ}$.

\section{Tropical soil}

Fungi and bacteria, and to a lesser extent actinomycetes, were clearly the major colonizers of chitin incubated in the tropical soil at $10^{\circ}$; at the higher incubation temperature besides these three groups, nematodes and protozoa were also recorded.

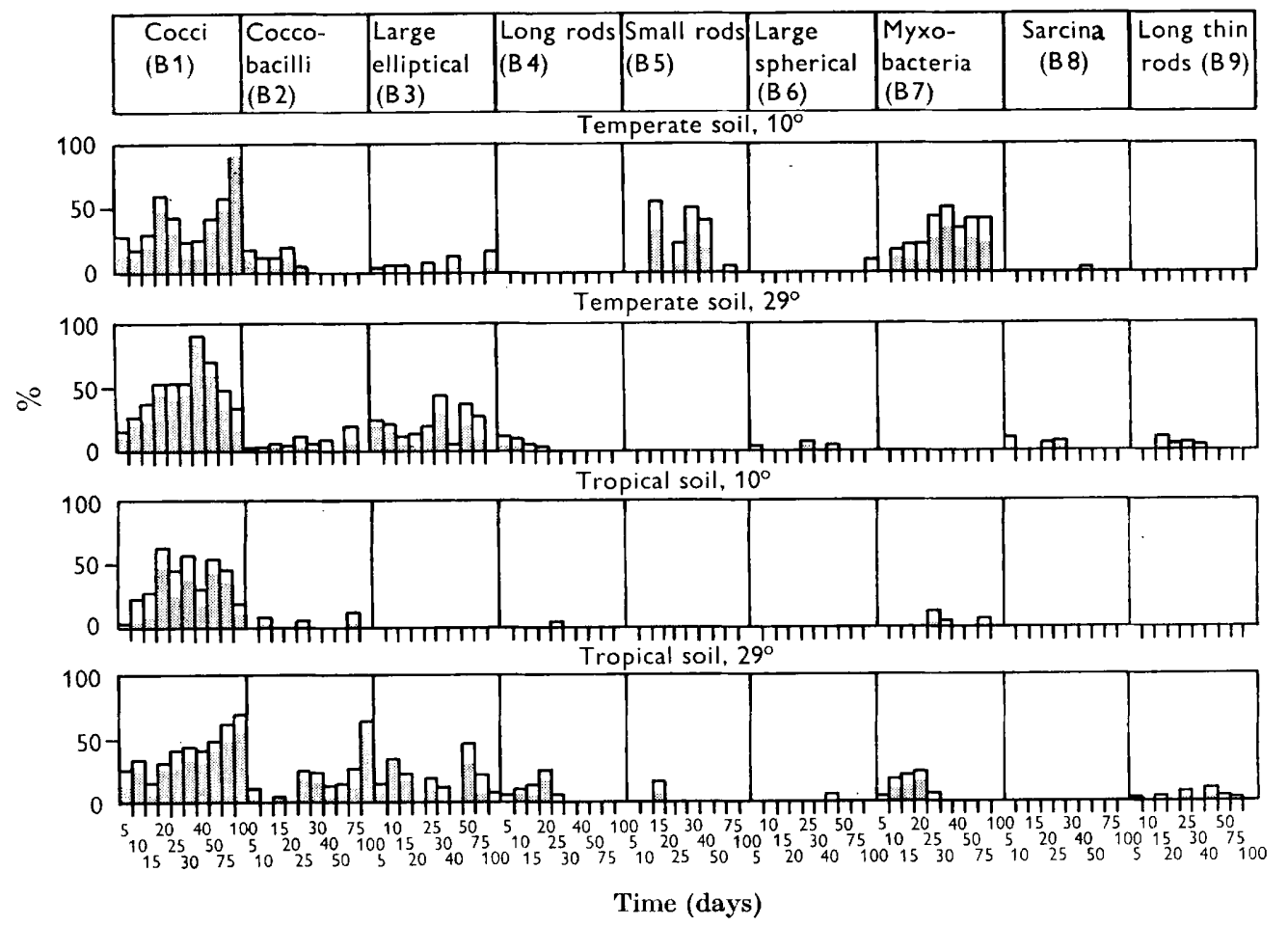

Fig. 5. Change with time in the percentage frequency of occurrence (empty boxes) and percentage constancy of dominance (dots within boxes) of the morphological subgroups of bacteria developing on chitin recovered from soil.

\section{Temperate soil}

\section{(b) Percentage frequency of occurrence of subgroups}

Fungi at $10^{\circ}$. Most of the fungal hyphae observed (Fig. 4) throughout the period of the experiment were aseptate (F2) narrow (3-6 $\mu$ ) irregularly sided, and closely packed. After rising from an initial value of $70 \%$, the percentage frequency of occurrence (p.f.o.) of the thin, aseptate hyphae (F2) rose to $97 \%$. Thereafter it declined sharply. On 75-day chitin pieces (Fig. 4) these hyphae had been completely replaced by wide $(6-10 \mu)$ septate brown rhizoctonia-like hyphae.

Fungi at $20^{\circ}$. Fungal hyphae observed up till the 15 th day were like at $10^{\circ}$, 
aseptate and irregularly sided. Unlike at $10^{\circ}$, however, they were wide (up to $10 \mu$ ) and loosely packed. They were replaced from the 20 th day onwards by thin aseptate hyphae of the type predominant at $10^{\circ}$. The p.f.o. of this latter type increased from $30 \%$ on the 20 th day to $83 \%$ on the 75 th day. Fungi on chitin pieces identified by their morphological characteristics were members of the genera Mucor and Mortierella; the hyphae of these fungi are normally non-septate. Although the p.f.o. of septate hyphae was low (Fig. 4) sporing structures belonging to fungi with septate hyphae were observed, species of the genera Aspergillus and Chaetomium.

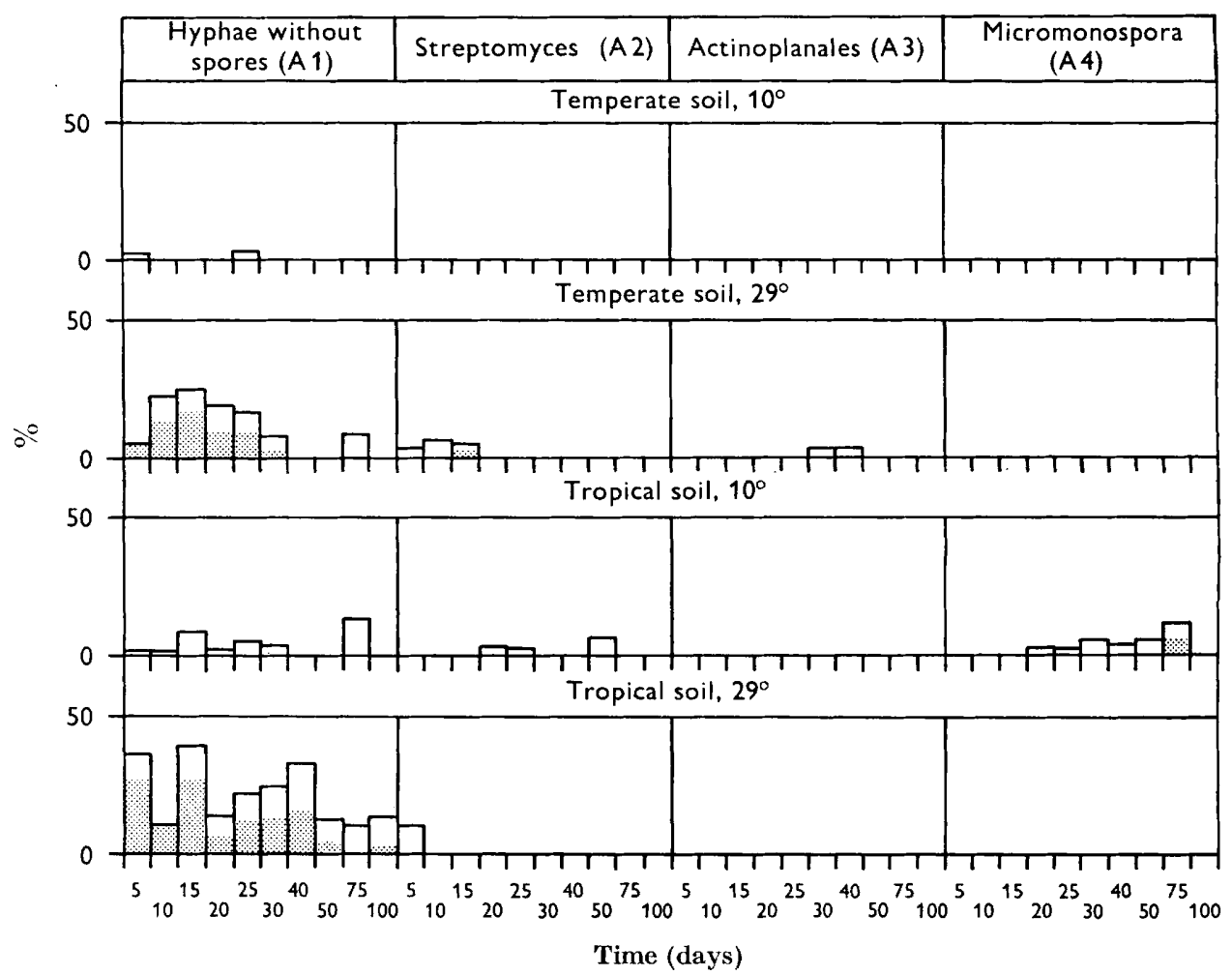

Fig. 6. Change with time in the percentage frequency of occurrence (empty boxes) and percentage constancy of dominance (dots within boxes) of the morphological subgroups of actinomycetes on chitin recovered from soil.

Bacteria at $10^{\circ}$. Among the subgroups of bacteria B 1, B 2, B3, B5 and B 7 were the most prominent; $\mathrm{B} 1, \mathrm{B2}$, and $\mathrm{B} 3$ were the only subgroups present at 5 days (Fig. 5).

Bacteria at $29^{\circ}$. At the higher temperature (Fig. 5) B 7 was completely absent. It is interesting to observe that while the p.f.o. of the subgroup B2 increased with time at $29^{\circ}$, it declined at $10^{\circ}$.

Actinomycetes. Actinomycetes (Fig. 6) were almost completely absent at $10^{\circ}$; at $29^{\circ}$ they occurred mainly as vegetative hyphae (A 1). Other sub-groups identified were A 2 (Streptomycetes) and A 3 (Actinoplanales) at $29^{\circ}$.

Protozoa. As was the case with actinomycetes, protozoa (Fig. 7) occurred mainly 


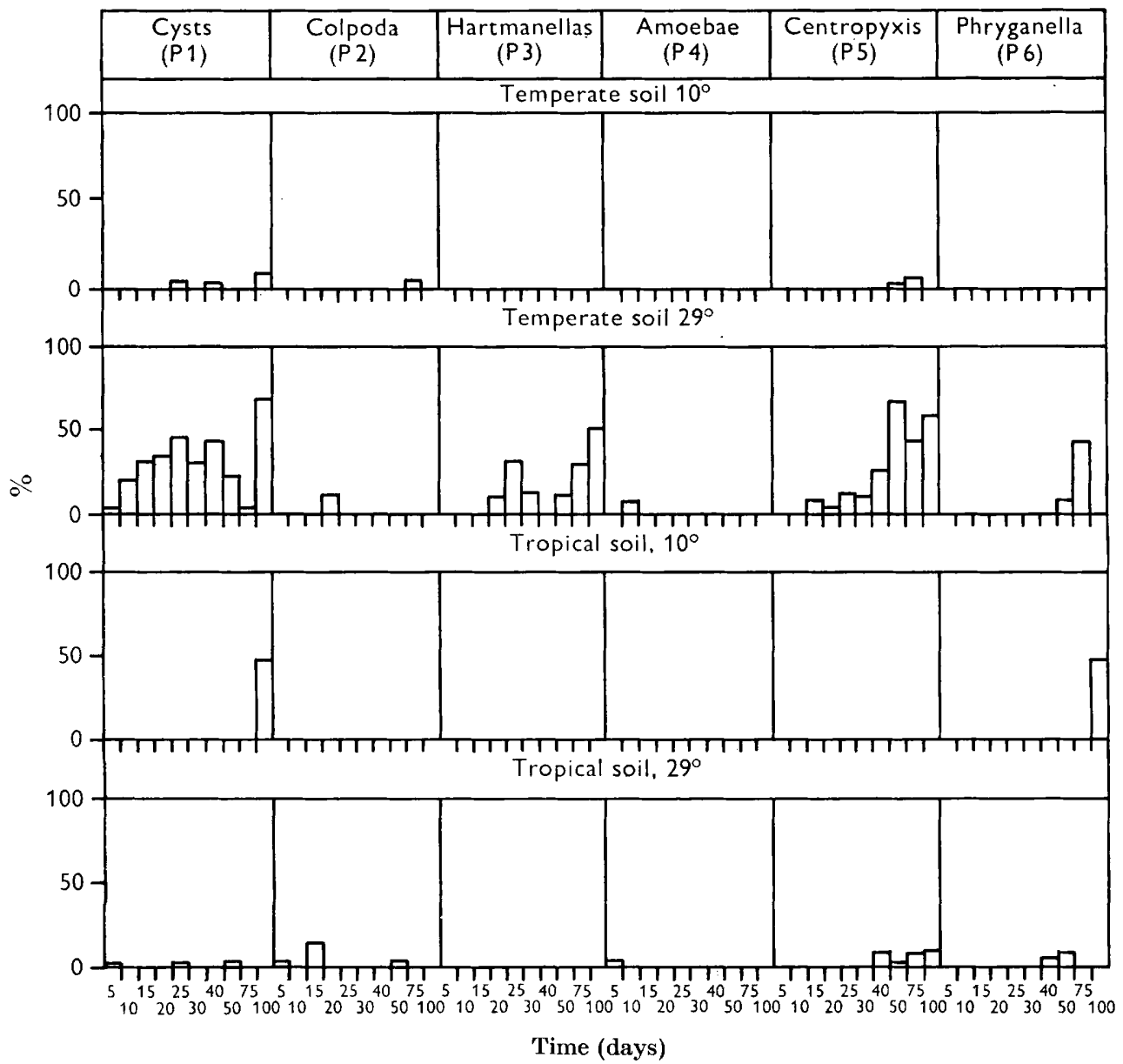

Fig. 7. Change with time in the percentage frequency of occurrence of the morphological subgroups of protozoa developing on chitin incubated in soil.

at $29^{\circ}$. The most abundant were P1 (non-testate amoeba cysts), P2 (cysts of colpoda), P3 (hartmanella species).

\section{Tropical soil}

Fungi. In contrast to the temperate soil the fungal hyphae observed on chitin pieces recovered from the tropical soil were mainly septate $(\mathrm{F} 1)$ both at $10^{\circ}$ and $29^{\circ}$. In general, the p.f.o. of fungal hyphae was higher at $29^{\circ}$ than at $10^{\circ}$ (Fig. 4). At $29^{\circ}$ numerous black-staining perithecia were observed from the 25th to 75th day Where spores were freely exposed they were oval and resembled those of Thielavia (Pl. 2, fig. 6).

Bacteria. At $10^{\circ}$ the subgroup (Fig. 5) most frequently occurring was B1. At $29^{\circ}$ others represented to any extent (besides $\mathrm{B} 1$ ), were B3, B 4, B 7 and $\mathrm{B} 9$.

Actinomycetes. As with temperate soil actinomycetes (Fig. 6) were present mainly as vegetative hyphae (A 1 ) with no sporing structures attached at both temperatures of incubation. Members of the genus Micromonospora (A4) occurred only at $10^{\circ}$. 
Protozoa. Protozoa were represented by only P1 and P5 at $10^{\circ}$ and then only on the 100th day chitin pieces. At $29^{\circ} \mathrm{P} 1$ (colpoda), P5 (centropyxis), P6 (phryganella) were represented, but their p.f.o. values were generally low (Fig. 6).

\section{(c) Percentage constancy of dominance of subgroups}

The constancy of dominance determinations (Figs. 4-6) have enabled a clear demonstration of the following: (i) On chitin recovered from the temperate soil no matter the temperature of incubation the most widely distributed fungal material on chitin were aseptate hyphae (F2); on the other hand, septate hyphae (F1) were predominant on chitin incubation in the tropical soil. (ii) Among bacteria B1 (cocoid bacteria) predominated at both temperatures in both soils, while B3 (large elliptical bacteria) were predominant at the higher temperature. B5 (small rods) and $\mathrm{B} 7$ (myxobacteria) were also predominant in the temperate soil at $10^{\circ}$, and B2 (cocco-bacilli) and B7 (myxobacteria) in the tropical soil at $29^{\circ}$. (iii) Actinomycetes occurred on chitin, mainly at the higher temperature.

\section{Colonization of glass coverslips by micro-organisms}

The observations made on the control are included in Fig. 3. Only the p.f.o. of the major groups was determined. Members of the subgroups were not abundant enough to warrant detailed observations. Figure 3 illustrates that few microbial structures were observed on the glass coverslips; the most abundant of those occurring were fungal hyphae and bacteria.

Among the frequently occurring fungal propagules were conidia of the genera Fusarium (temperate soil) and perhaps Curvularia (tropical soil). About the same frequency of septate (F1) and aseptate (F2) hyphae were observed on control coverslips recovered from both soils.

Bacteria were distributed in discrete patches, usually around soil particles or organic matter, e.g. fungal hyphae. Most of the bacteria were B1 (cocci) or B2 (cocco-bacilli).

\section{Decomposition of chitin as determined by loss of material}

No loss of material from chitin pieces was observed when chitin was incubated in the temperate soil at $10^{\circ}$ until the 15 th day; at $29^{\circ}$ chitin pieces were intensely decomposed at 5 days although all pieces were recoverable (Table 4). Decomposition of chitin was not observed in pieces recovered from the tropical soil at $10^{\circ}$ until the 75 th day and only after 10 days at $29^{\circ}$.

\section{DISCUSSION}

Besides eliminating the selectivity inherent in the dilution technique and also preserving the micro-habitats, the direct microscopic method used in this experiment has the further advantage that the sizes of chitin added were more nearly similar to those added under natural conditions: in the dilution technique the substrates if insoluble in water are nearly always finely ground. Furthermore, organisms seen at any given time are observed in the morphological forms in which they actually exist in soil.

But this method also has disadvantages. First, morphological characteristics are not always sufficient criteria for classifying micro-organisms especially bacteria. 
In such cases, physiological tests are also necessary. Secondly, misidentification of an organism may occur if it assumes in soil forms other than those usually observed in pure cultures. Thirdly, this method can only be used for materials which are obtainable in large sheets.

The factors which influenced the quantitative distribution of organisms on chitin apart from the genetical constitution of the organisms themselves may be considered under the following two heads:

(a) The influence of environmental conditions. Chitin was incubated in both soils at $10^{\circ}$ and $29^{\circ}$. For each soil the only environmental factor which was varied was the temperature of incubation. The higher temperature clearly selectively encouraged a greater abundance of actinomycetes, nematodes and protozoa. It may be expected that the observations made on chitin in the temperate soil at $10^{\circ}$ are more likely to occur under natural conditions, while in the case of tropical soil those at $29^{\circ}$ are more likely. It is interesting that in many previous ecological works on chitin actinomycetes have been implicated as the major chitinolytic organisms. These experiments (e.g. Jensen, 1932, Veldkamp, 1955) have been carried out at temperatures of $25-30^{\circ}$. Since these soils were temperate soils it is still to be discovered whether the laboratory observation of these workers are a true reflexion of field situation where temperatures are never so high.

(b) The availability of propagules. The viable propagules of organisms able to utilize chitin (or break down products released from it by the activities of other organisms) must be present at a distance sufficiently close to the appropriate substrate to be stimulated to develop. The more unevenly distributed the viable propagule of an organism is, the more the number of pieces necessary for it to be represented on the ecological observations. In this experiment a fairly large number of chitin pieces has been placed in a small amount of soil to enable as much contact as possible to be made between the chitin pieces and the propagules of the organisms. The factor:

number of chitin films in which organisms occurred number of chitin films examined

which was used in deriving the 'percentage constancy of dominance' helped to distinguish organisms whose viable propagules were well distributed from other organisms whose organisms were not.

The colonization of the subtrate results in its utilization and eventual exhaustion and decomposition (Garrett, 1955). Although the experiment was concerned mainly with studying the ecological distribution of micro-organisms, the amount of decomposition taking place was estimated by noting loss of material from the central and uncut edges of the chitin films; the method is subjective and approximate. As might be expected, in each soil, the decomposition of chitin occurred earlier at the higher temperature. Since the lower temperature $\left(\mathbf{1 0}^{\circ}\right)$ is close to that found in soil in Cambridge, at least for part of the year, it is tempting to speculate that chitin placed in situ in the field from which the experimental soil was collected, would not show much loss in the original material until about the tenth day. Similarly, chitin of the same chemical composition as that used in this experiment would show little loss of material until the fifteenth day in the Moor Plantation soil in situ, the time after which loss of material was observed in chitin buried in the Ibadan soil at $29^{\circ}$. 
This will be true of course only if: (1) drying the soil before use (as was done in this experiment) does not seriously alter the proportion of micro-organisms responsible for the loss of materials; (2) other soil organisms not recorded in this experiment, e.g. insects and mites, do not in any way influence the rate of loss of material; (3) fluctuations in the environmental conditions, especially the soil moisture-content, do not influence the activities of the organisms observed.

This paper is abstracted from a thesis approved for the Ph.D. degree of the University of Cambridge. I wish to thank Dr H. T. Tribe for helpful suggestions and the Government of the Federal Republic of Nigeria for providing the funds. Thanks are also due to Dr $\mathbf{O}$. W. Heal and the late Dr J. B. Goodey respectively for identifying the protozoa and nematodes.

\section{REFERENCES}

Bergey's Manual of Determinative Bacteriology . (1957). Ed. by R. S. Breed, E. G. D. MURRAY, and R. N. SMith. Baltimore: Williams and Wilkins.

Brown, D. (1954). Methods of Surveying and Measuring Vegetation. Commonwealth Agricultural Bureau.

Chase, F. E. \& Gray, P. H. H. (1957). Application of the Warburg respirometer in studying respiratory activity in soil. Can. J. Microbiol. 3, 335.

Foster, A. B. \& Webrer, F. W. (1960). Chitin, Advanc. Carb. Chem. 15, 371.

Garrett, S. D. (1955). Microbial ecology of the soil. Trans. Br. mycol. Soc. $38,1$.

Gilman, J. C. (1957). A Manual of Soil Fungi. Iowa State College Press.

Gray, T. R. G. \& BELL, T. F. (1963). The decomposition of chitin in an acid soil. In Soil Organisms. Ed. by J. Doeksen and J. van-der Drift. Amsterdam: North Holland Publishing Co.

Greig-Smith, P. (1964). Quantitative Plant Ecology. London: Butterworths.

Hanson, H. C. \& Churchill, E. D. (1961). The Plant Community. New York: Reinhold.

Jensen, H. L. (1932). The microbiology of farm yard manure decomposition in soil. 3. Decomposition of micro-organisms. J. agric. Sci. 22, 1.

Jensen, H. L. (1934). Contribution to the microbiology of Australian soils. 2. A comparison of the Rossi-Cholodny method and the plate method for studying soil microflora. Proc. Lin. Soc., N.S.W. 59, 200.

Kevan, D. K. M. (1955). Soil Zoology. London: Butterworths.

Kunnelt, W. (1961). Soil Biology. London: Faber and Faber.

ODUM, E. P. (1960). Fundamentals of Ecology. London: Saunders.

OKAFor, N. (1964). Studies on the microbiology of decomposition in soil with particular reference to chitin degradation. Ph.D. Thesis, University of Cambridge.

OKaFor, N. (1965). Isolation of chitin from the shell of Sepia officinalis L. Biochim. biophys. Acta 101, 193.

Richards, A. G. (1951). The Integument of Arthropods. University of Minnesota Press.

Rudall, K. M. (1955). The distribution of collagen and chitin. Symp. Soc. exp. Biol. 9, 49.

Sacchs, I. B. (1956). The chemical nature of the cyst membrane of Pelomyxa illinoinensis. Trans. Am. microscop. Soc. 75, 307.

Salt, G. (1953). The arthropod population of some Fast African pastures. Bull. Ent. 43, 203.

Sandon, H. (1927). The Composition and Distribution of the Protozoan Fauna of Soil. Edinburgh: Oliver and Boyd.

Singt, B. N. (1952). Nuclear division in nine species of small free-living amoebae and its bearing on the classification of the order Amoebida. Phil. Trans. R. Soc. B 236, 405.

Skinner, C. E. \& Dravis, F. (1937). A quantitative determination of chitin destroying micro-organisms in soil. Ecology 18, 391.

SмIтн, G. (1960). Introduction to Industrial Mycology. London: Arnold. 

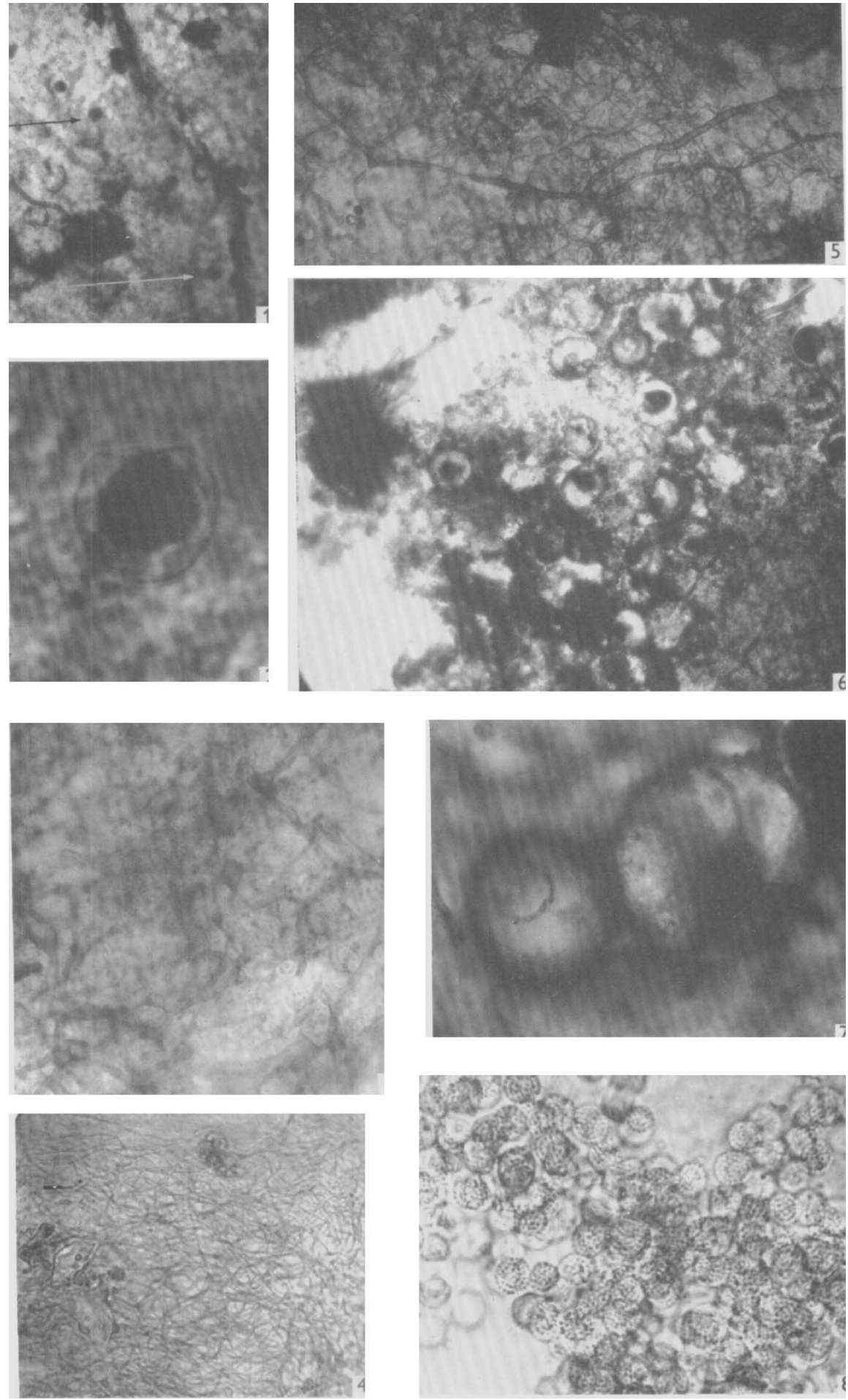

N. OKAFOR

(Fraing p. 326) 

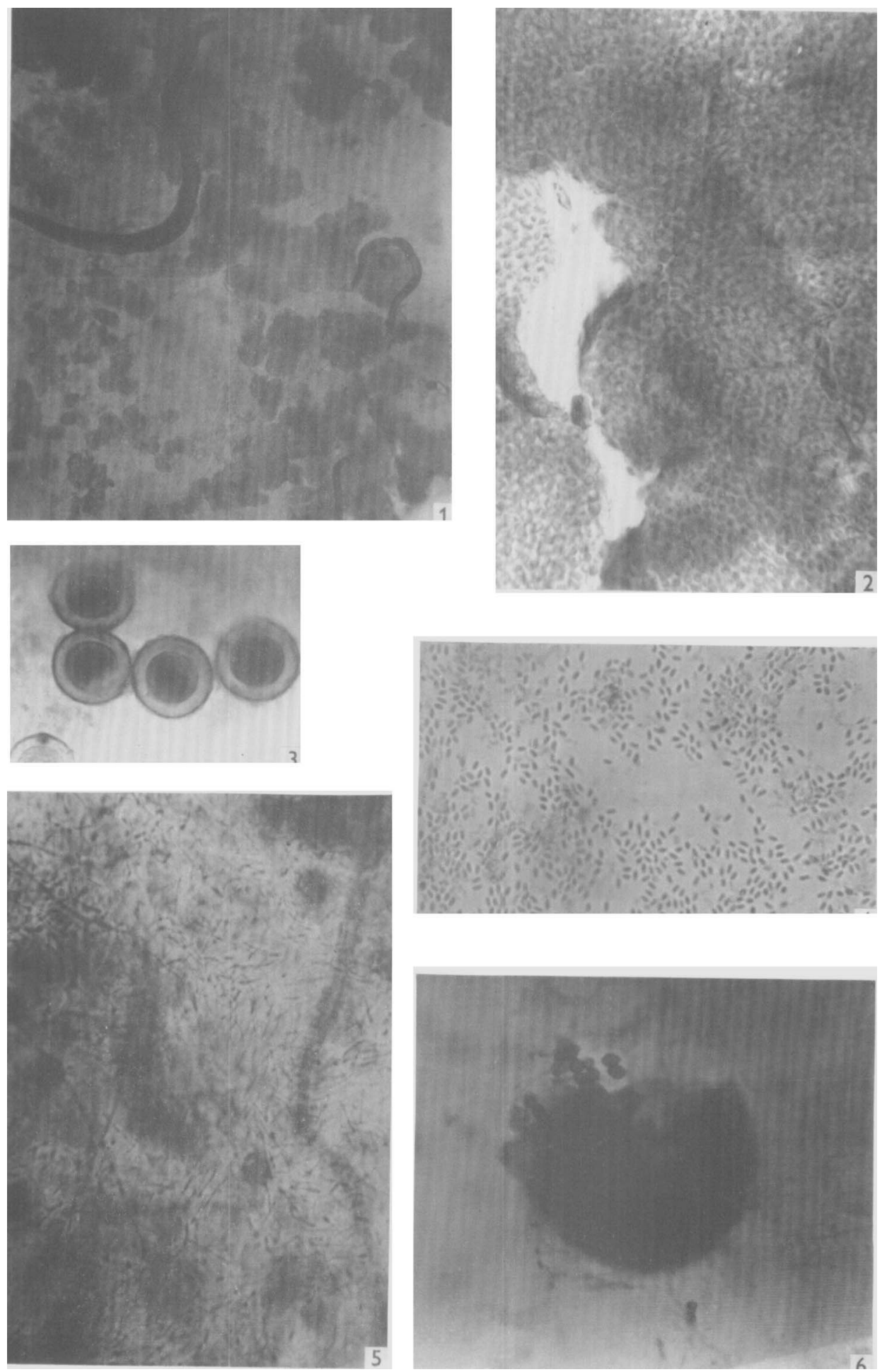

N. OKAFOR 
Tracey, M. V. (1955). Chitin. In Modern Methods of Plant Analysis. Ed. by K. Paech and M. V. Tracey. Berlin: Springer-Verlag.

TrIBE, H. T. (1957). Ecology of micro-organisms in soils as observed during their development upon buried cellulose film. Symp. Soc. gen. Microbiol. 7, 287.

VELDKAMP, H. (1955). A study of the aerobic decomposition of chitin by micro-organisms. Meded. LandbHoogesch. Wageningen 55, 127.

Whistler, R. L. \& Smart, C. L. (1953). Polysaccharide Chemistry. New York: Academic Press.

\section{EXPLANATION OF PLATES}

\section{Plate 1}

Fig. 1. Protozoa (P 4) (arrows) developing on chitin buried in the temperate soil at $20^{\circ}$ for 10 days. $(\times 160)$.

Fig. 2. Protozoa (P 4) magnified. ( $\times$ 1000.)

Fig. 3. Coccoid bacteria arranged in groups of 2,4 or 8 and enclosed in a non-staining capsule (B 8), on chitin incubated in the temperate soil at $29^{\circ}$ for 40 days. $(\times 1000$.)

Fig. 4. Vegetative actinomycete hyphae (A 1). $(\times 1000$. $)$

Fig. 5. Wide aseptate hyphae (F2) observed on chitin incubated in the temperate soil at $29^{\circ}$ for 5 days. $(\times 220)$.

Fig. 6. Testate protozoa, Centropyxis minuta (P5) on chitin incubated in the temperate soil at $29^{\circ}$ for 40 days. A perithecium of a fungus, Chaetomium sp. is slightly out of focus in the left. A nematode is present on the right hand corner. $(\times 220$.)

Fig. 7. Part of fig. 6 magnified to show Centropyxis minuta $(\mathrm{P} 5) .(\times 1000$.

Fig. 8. Sporangia of actinomycetes belonging to the genus Actinoplanales observed on chitin. $(\times 1000$.$) .$

Plate 2

Fig. 1. Cysts of bacteria probably belonging to the genus Archangiaceae (B 6). Nematodes are also present. The chitin piece was incubated in the temperate soil at $29^{\circ}$ for 10 days. $(\times 220$. $)$

Fig. 2. Cysts of B 6 magnified. ( $\times$ 1000.)

Fig. 3. Cysts of protozoa P2; probably a colpoda species. $(\times 1000$.)

Fig. 4. Bacteria B 3 developing on chitin. $(\times 1000$.)

Fig. 5. Long rod-like bacteria sometimes with spore-like structure at one end, observed on chitin recovered from the tropical soil incubated at $29^{\circ}$ for 20 days. $(\times 1000$.)

Fig. 6. Cleisothecium of a fungus probably belonging to genus Thielavia regularly observed on chitin recovered from the tropical soil from the 15 th to the 75 th day of incubation at $29^{\circ}$. 